\title{
Theoretical, behavioral and neuroimage evidence on discourse processing aging
}

\author{
Bernadette Ska ${ }^{1}$, Lilian Cristine Scherer ${ }^{1,2}$, Onici Claro Flôres ${ }^{2}$,Camila Rosa de Oliveira ${ }^{3}$, Tânia \\ Maria Netto ${ }^{4}$ and Rochele Paz Fonseca ${ }^{3}$ \\ 1 Université de Montréal, Canada \\ 2 Universidade de Santa Cruz do Sul, Brazil \\ 3 Pontifícia Universidade Católica do Rio Grande do Sul, Brazil \\ 4 Pontifícia Universidade Católica do Rio de Janeiro, Brazil
}

\begin{abstract}
A growing interest in cognition in aging has been observed because of both the epidemiologic factor of an increase in the lifespan of the world's population and the cognitive changes behaviorally and biologically detectable in this population. The most complex of language components and fundamental in social interaction, discourse production and comprehension are among the most scarcely explored cognitive functions in this context. This review presents and discusses discourse processing in healthy aging with regard to theoretical, behavioral, and neuroimaging evidence. Cognitive and neurobiological models are reviewed, such as the Hemispheric Asymmetry Reduction in Older Adults (HAROLD) model and the Posterior-Anterior Shift in Aging (PASA) model. Among the neuropsycholinguistic research developed to characterize discourse processing in aging individuals, which has contributed to the prevention and treatment of language impairment and the maintenance of communicative competence in aging, studies on the relationship between discourse and working memory, attention, and some executive components are discussed. Regarding neuroimaging data, very few studies that have included cognitive tasks and discourse stimuli were found. Such studies suggest that discourse processing requires not only the participation of both brain hemispheres, but also a more prominent activation of frontal regions. Considering the great complexity and usefulness of discourse in elderly adults' daily communication and the emergence of cognitive deficits related to aging in complex information processing, the necessity of further behavioral and neuroimaging studies, including discourse processing tasks, comparing tasks involving executive, attentional, and mnemonic demands becomes evident. Keywords: aging, discourse, cognitive assessment, functional neuroimaging.
\end{abstract}

Received 29 November 2009; received in revised form 29 December 2009; accepted 29 December 2009. Available on line 29 December 2009.

\section{Introduction}

The basis of healthy aging has become an important research field in the 21st century. This may be the case, at least partially, because of the fact that in most developed countries average life expectancy has increased from about 45 years in 1900 to about 75 years in $1990(\mathrm{Li}$

Lilian Scherer, Centre de Recherche Institut Universitaire de Gériatrie de Montréal (CRIUGM) et Faculté de Médecine, Université de Montreal. Lilian Scherer and Onici Claro Flores, Programa de Pós-Graduação em Linguagem e Literatura, Universidade de Santa Cruz do Sul, Brazil. Camila Rosa de Oliveira and Rochele Paz Fonseca, Post-Graduation Program of Psychology, Human Cognition, Clinical and Experimental Neuropsychology Research Group, Pontifícia Universidade Católica do Rio Grande do Sul, Brazil. Tânia Maria Netto, Departamento de Psicologia, Pontifícia Universidade Católica do Rio de Janeiro, Brazil. Correspondence regarding this article should be directed to: Bernadette Ska, 4565, Chemin de la ReineMarie, Montreal, Quebec, H3W 1W5, Canada. Phone: (514) 3403540 ext. 4006. E-mail: bernadette.ska@umontreal.ca
\& Dinse, 2002). Adults older than 65 are expected to represent $12.6 \%$ of the Brazilian population in 2010, while in Latin America, during this same period, the percentage will be 11.9\% (Comición Económica para América Latina y el Caribe, 2009). Therefore, with the rapid growth of the world's population (Li \& Dinse, 2002), a better understanding of the mechanisms and processes influencing cognitive and sensorimotor aging is essential to reduce its occurrence or at least its speed of decline. Moreover, a better understanding of the phenomena accompanying cognitive aging allows psychologists, clinicians, linguists, and professionals in other related areas to assist the elderly population in the process of enhancing individual and environmental compensatory abilities. Communication mastery is one of the most powerful tools on which aged people rely to gain or maintain social participation. Thus, the study of discourse processing, the most complex linguistic unit, may contribute to the diagnosis, prevention, minimization, and treatment of discourse production and comprehension difficulties which may be generated by aging. 
The aim of this non-systematic review is to present and discuss the characteristics of discourse processing in the healthy elderly population based on theoretical, behavioral, and neuroimaging evidence. For this purpose, relevant theories and neuropsychological and neuroanatomical aspects that may influence this cognitive processing will be considered.

\section{Theoretical evidence}

Discourse processing is built on the information driven by linguistic cues in written texts or oral speech and from background knowledge brought by the reader or listener. Furthermore, the reader or listener must interconnect these types of information and build a mental representation of the text, referred to by Kintsch and Van Dijk (1978) as the "situation model.” In aging, certain changes appear to occur in the way readers and listeners process discourse. Theoretical evidence that can be used to explain cognitive changes in discourse processing may be represented by the following categories: (i) the cognitive hypothesis and (ii) neurobiological models.

Among the first theoretical group, corroborating the cognitive hypothesis, the interplay between changes in attentional and executive function and working memory and their effects on language processing in aging has led to the postulation of different theories of language capacity in elderly individuals. A major association has been made between working memory and discourse complexity. For example, a study by Miller (2009) investigated age-related differences in the effects of semantic knowledge on the efficiency by which written information is processed. Elderly participants, not younger adults, demonstrated improved reading capacity when they had background knowledge about the content of the text (in this case, cooking knowledge). Experience with the topic of the text also helped elderly participants with lower working memory capacity, suggesting that content knowledge enhances effective reading and reduces working memory demands. Federmeier, Van Petten, Schwartz, and Kutas (2003) postulated two assumptions to explain language processing in aging: one that assumes the occurrence of a generalized slowing in language functioning attributable to global neurobiological changes, and another that postulates the existence of a reduction in specific cognitive processing resources. Thornton and Light (2006) classify the latest approaches that aim to explain age-related changes and stability in cognition into five groups: (1) cognitive slowing, (2) impairment in working memory and consequent interference in storage and manipulation of information, (3) weakened inhibitory processes that could inhibit the activation of information irrelevant to the task to be solved, (4) weakened connections among memory representations that reduce the transmission of excitation (i.e., the transmission deficit), and (5) the emergence of sensory deficits. Research has found evidence to corroborate all of these theories. Therefore, further investigation is still needed for a thorough understanding of the underlying basis of age-related differences in language processing at different levels.

As stated by Thornton and Light (2006), current approaches in cognitive changes in aging have investigated the relationships between sensory, phonological, orthographic, lexical, syntactic, and semantic processing linked to top-down or bottom-up approaches and have revealed a tendency for conceptually driven (top-down) processing as the preferred approach in aging. Moreover, the authors mention that recent research has also analyzed the possible occurrence of redefined goals, an increase in expertise, and application of compensatory strategies as potential factors in language and general cognitive functioning in aging.

The second category, which encompasses the neurobiological models, includes some importantmodels that attempt to explain age-related differences in brain function and cognition. Some examples are the Compensation Related Utilization of Neural Circuits (CRUNCH) model (Reuter-Lorenz \& Mikels, 2005), the Cognitive Reserve (CR) hypothesis (Stern et al., 2003), the Hemispheric Asymmetry Reduction in Old Adults (HAROLD) model (Cabeza, Anderson, Kester, \& McIntosh, 2002), and the Posterior-Anterior Shift in Aging (PASA) model (Davis, Dennis, Daselaar, Fleck, \& Cabeza, 2008).

The CRUNCH model suggests the occurrence of an additional neural circuitry to cope with declining neural efficiency. The authors state that compensation can occur in several ways, such as bilateral recruitment of homologous brain regions or by recruitment of different brain regions for older and younger adults. The model assumes that older adults will reach their resource limits sooner, thus predicting: “(1) poorer performance for older than for younger adults on more complex tasks and (2) under-recruitment for old relative to younger adults as tasks become more difficult. Older adults should show a smaller change as compared to younger adults in PET or fMRI activation as tasks become more difficult” (Kramer, Fabiani, \& Colcombe, 2006, p. 68). As stated by Kramer et al. (2006), this model needs further validation with different tasks and populations to determine its generalizability.

The CR hypothesis assumes that the ability of older adults to cope with advancing brain pathologies is generated either by a set of acquired skills or by inherent abilities. This hypothesis is related to the level of education, Intelligence Quotient, occupational status, and other lifestyle factors (Stern et al., 2003; Stern, 2009). These variables may account for different degrees of brain pathologies among aged people. That is, individual differences in terms of the number of years of formal education, for example, may explain why the degree of brain pathology does not always match the 
expected cognitive problems among elderly individuals. Tests of this model have shown changes in brain region activation as a function of task difficulty, suggesting that different neural networks subserve difficulty-based compensation in older compared with younger adults (Dennis \& Cabeza, 2008).

Another model that aims to explain the underlying brain circuitry of cognition and performance in aging, the HAROLD model, posits that brain activity appears to be less lateralized in older adults than in younger ones (Cabeza, Anderson, Locantore, \& McIntosh, 2002). A growing concern has been the role of each cerebral hemisphere in the processing of language components in aging, and a combination of imaging and behavioral studies has gradually been designed to investigate this issue (Ansaldo, Monchi, Roy, \& Doyon, 2005; Nunes, Castro-Caldas, Del Rio, Maestú, \& Ortiz, 2009). The assumption of a hemispheric asymmetry reduction in older adults with high performance when computing cognitive tasks is supported by functional neuroimaging investigations and studies on episodic and semantic memory, working memory capacity, perception, and inhibitory control (Cabeza et al., 2002; Cabeza et al., 2004). For example, studies by Kramer et al. (2006) on episodic encoding, episodic retrieval, working memory, and face matching have shown bilateral activation in older adults compared with more right- or left-lateralized functioning in younger adults. These authors mentioned a study by Reuter-Lorenz et al. (2000), in which data were recorded while older and younger adults solved a verbal and spatial working memory task. In the frontal lobes of younger adults, activation was more left-lateralized for verbal and right-lateralized for spatial working memory, whereas older adults showed more bilateral activation for both types of memory tasks. Moreover, some studies have argued that older adults who perform better on a task have shown bilateral activation of homologous areas, whereas those who perform more poorly have shown unilateral activation (Cabeza et al., 2002). However, these results have not been corroborated by other studies, which found no relationship between laterality and performance or revealed unilateral prefrontal activation in better performing older adults and bilateral prefrontal activation in poorer performing older adults (for review, see Kramer et al., 2006). In summary, specifically with regard to memory in aging, the literature appears to suggest a general compensatory role for the temporoparietal and prefrontal regions across different memory tasks in elderly people (Kramer et al., 2006).

According to Dolcos, Rice, and Cabeza (2002), two models account for hemispheric asymmetry in aging: the right-aging model, which postulates that the right hemisphere shows higher age-related decline than the left hemisphere, and the HAROLD model, which suggests that frontal activation during cognitive tasks tends to be less lateralized in older than in younger adults. A literature review of positron emission tomography (PET) and functional magnetic resonance imaging (fMRI) studies on cognitive task performance in aging developed by Cabeza et al., (2002) postulates the existence of higher activation in the right hemisphere in older adults compared with younger adults. According to the author, this reduced asymmetry may reflect a compensatory mechanism to cope with a possible neurocognitive decline or a de-differentiation process, which may provide evidence of difficulties in recruiting specialized neural mechanisms.

Finally, corroborating the occurrence of functional brain reorganization in aging, Davis et al. (2008) recently described the PASA model, which represents a third model to explain hemispheric asymmetries. According to these researchers, a reduction in occipital activity occurs in aging that correlates with increased frontal activation as a means of maintaining previous levels of cognitive performance. Increases in parietal activity were also found. The researchers suggest that an increase in frontal activity occurs despite the occurrence of high levels of task difficulty; that is, frontal activation represents a compensatory strategy to maintain high levels of performance.

Relating the models of neurofunctional organization in aging presented above to discourse processing, this reorganization certainly affects the way elderly individuals process discourse. Behavioral and neurofunctional changes are expected to occur while this group of individuals reads or writes text, compared with younger adults, which will be further discussed in this article.

The development of research on cognitive aging intrinsically relates to individual differences. That is, researchers cannot ignore the impact of individual differences on data obtained from behavioral and imaging studies. Discourse processing is not an exception because some individual differences interfere in the way older adults process text. For example, agerelated differences in reading comprehension and recall appear to be larger when comparing young adults with old adults (70 years of age and older). However, when older participants have an advantage in vocabulary or intelligence over younger ones, differences related to age are smaller (Meyer \& Pollard, 2006). Thus, an advantage in vocabulary or intelligence is able to reduce possible deficits in reading comprehension and recall in the aged population.

A decline in the performance of elderly populations in language activities can be linked to changes in attention and executive function, including inhibitory control. These changes may lead to a generally slowed speed of information processing, difficulties in distinguishing between important and irrelevant information, and difficulties in processing two types of information at the same time (Ska \& Joanette, 2006). Furthermore, with regard to individual differences in memory, recognizing 
that our memory system can be divided into different subsystems-episodic, semantic, procedural, and working memory (Ska \& Joanette, 2006)-is important, with each subsystem differentially affected by aging. For example, semantic memory, including vocabulary acquisition, has been shown to continue to improve with age (Verhaeghen, 2003), whereas a major impact tends to be observed in working memory processing (Andrés, Guerrini, Phillips, \& Perfect, 2008). Similarly, inhibitory and excitatory mechanisms are modulated by individual differences, leading to a higher or lower reduction in inhibitory control and resistance to interference when elderly adults perform higher-level tasks (Andrés et al., 2008). According to these studies, the degree of capacity of inhibiting irrelevant information may, in turn, affect working memory capacity.

Another important issue related to individual differences in aging is provided by the concept of cognitive resources available while a person gets older. According to Baltes (1997), cognitive resources may be classified into two fundamental types: those brought by birth, on which one can count (from nature), and those developed over the course of a lifetime through learning and practice (from nurture). The concept of cognitive resources is directly related to the concept of brain plasticity, in the sense that the amount of resources available brought both by birth and experience, may be accommodated by brain structures and functioning. As stated by Ska and Joanette (2006), certain individual characteristics may modulate cognitive resources. Among these, the authors include cognitive styles (analytic or global), the type and level of education, personality traits, health conditions, the type of knowledge or experience (determined by studies or professional experience), and lifestyle.

Thus, some individual differences in aging appear to be related to the concept of "successful aging," "well aging," or still "healthy aging," and may be determined by different individual levels of maintenance of physical, mental, and social autonomy (Von Faber et al., 2001), which may affect elderly adults' performance. The concept of "successful aging" can be defined according to different facets: cultural (Western and other cultures), perspective (that of the researcher or the elderly person), and content (biomedical or holistic; for a detailed explanation, see Gangbè \& Ducharme, 2006). Gangbè and Ducharme (2006) stated that the models that try to explain the "successful aging" concept can be divided into two broad groups: one-dimensional models, which base their assumptions on a single scientific discipline (i.e., the Biologic, Cognitive, and the Psychosocial Models), and multicriteria models, which integrate different scientific perspectives. Gangbè and Ducharme suggested that the integration of the various models could lead researchers to aid in the promotion of more effective "successful aging" programs in the future.
Altogether, the aspects discussed above could be grouped into aging models of language processing, as proposed by Craik and Salthouse (2008): (i) resource theory (based on the assumption that human capacity for processing information is limited), (ii) inhibition deficit theory (aging weakens inhibitory processes that regulate attention and the contents of working memory, thus influencing language production and comprehension), (iii) working memory theories (aging reduces working memory capacity, which constrains older adults' ability to comprehend and produce complex semantic content and syntactic structures), and (iv) transmission deficit theory (aging weakens connection strengths among representational units).

Correlating these theoretical perspectives to discourse processing in aging, concluding the difficulty in circumscribing discourse relationships to specific brain areas in aging appears possible. This happens because of the variety of brain activation patterns described in the literature, which may occur as a consequence of varied compensatory strategies and the individual differences found in this group, caused by varying degrees of maintenance of cognitive capacities, such as working memory and inhibitory and attentional control.

\section{Language processing and neuropsychological changes: behavioral and neuroimaging evidence}

As reported in the literature, language and communication processes in aging may be affected by the interplay of an array of variables, such as changes in attention (Silver, Goodman, \& Bilker, 2009), executive function (Stemmer, 1999; Silver et al., 2009; Charlton, Barrick, Markus, \& Morris, in press), processing speed (Head, Kennedy, Rodrigue, \& Raz, 2009; Kennedy \& Raz, 2009), memory (Charlton, Barrik, Markus, \& Morris, 2009; Kennedy \& Raz, 2009; Silver et al., 2009), and working memory capacity (Allain et al., 2007; Head et al., 2009; Kennedy \& Raz, 2009; Silver et al., 2009). Some changes in the nervous system may also affect language and communication processing. These changes occur on a neurophysiological basis, such as a reduction in the size and number of neurons, a diminished efficiency in synaptic contacts, and other neurochemical changes, such as those shown through a reduction in the concentration of neurotransmitters, including dopamine (Raz, 2000; Tumeh et al., 2007; Gold, Andersen, Jicha, \& Smith, 2009). Additionally, disturbances in neuroanatomic structures, such as the prefrontal cortex (Allain et al., 2007), and a reduction in brain volume, both in gray and white matter (Raz, 2000; Charlton et al., 2009; Kennedy \& Raz, 2009; Rajah et al., 2009; Charlton et al., in press), have been demonstrated. Structural changes in the brain begin around the age of 30 , but the losses are not uniformthey appear to be greater in prefrontal regions, smaller 
in parietal and temporal regions, and less important and often nonsignificant in sensory and motor cortices (Raz, 2000; Rajah et al., 2009). Declines have also been reported in white matter, which have been more pronounced in frontal regions (Head et al., 2004). Studies have shown that changes in brain structure can affect both cognitive performance (leading to lower performance in tasks dependent on the areas that went through a volume reduction) and patterns of cortical recruitment (i.e., older adults frequently recruit other brain areas in addition to those recruited by younger adults; for review, see Kramer et al., 2006).

Both behavioral and neuroimaging studies have provided evidence of such changes. Some of these studies will be presented below, and the implications of their findings for discourse processing will be discussed. Some methodological implications will then be presented by considering both types of studies.

\section{Characterizing discourse processing in aging based on neuroimaging evidence}

Few studies on discourse processing by normal and non-healthy adults by means of neuroimaging techniques can be found in the literature. With regard to text processing in aging, the number of studies is even lower. Discourse is the language level least investigated by the use of neuroimaging techniques, possibly because of the restrictions imposed by them. Some of the limitations are the difficulty in visually presenting longer texts, the interference of scanner noise in auditory task presentation, and the position of the participants in the scanner (in the case of fMRI and PET), among others. These conditions reduce the ecological validity of the experimental condition. However, despite these and other limitations, some important evidence has already been provided by these studies, which have shed some light on how the aging brain processes text.

According to Grady, Springer, Hongwanishkul, McIntosh, and Winocur (2006), the most evident declines generated by aging can be observed in episodic memory, attention, and aspects of emotional perception, whereas no changes or even improvements have been found in semantic memory and aspects of social cognition, such as the processing of the theory of mind. Their fMRI study investigated age-related changes in brain activity across the adult lifespan and suggested the existence of different functional connectivity with age (i.e., the engagement of different brain networks by elderly people compared with younger ones). Such a difference may indicate the occurrence of a compensatory or different strategy to cope with a task. Moreover, these researchers found that the default mode (i.e., the brain areas that remain active when someone is not performing a task or thinking, for example, about errands) continues to be more active in older adults, which may explain their higher tendency to be distracted, suggesting that the default mode is supposed to be deactivated when an individual executes a task.

Similarly, Cook, O’Connor, Lange, and Steffener (2007) suggest the existence of differential connectivity in working memory circuits between younger and older adults. The authors postulate that this may reflect the effects of aging on white matter or compensatory mechanisms, among other possible factors.

An ERP study developed by Federmeier et al., (2003) postulated that a reduction in working memory capacity in aging may be more prominently detectable in higher-order language processes, such as complex sentences and discourse tasks, in which predictive processes become less likely or less efficient, rather than lower-order language processes, such as the processing of lexical associative relationships.

Three particular aspects have been investigated in working memory processing in aging: (i) age-related dissociations between declarative and non-declarative memory, (ii) the role of the left and right prefrontal areas in recollection and familiarity phenomena, and (iii) the role of the prefrontal cortex in working memory function (Kramer et al., 2006). Working memory is relevant in language processing, which has been conveyed by several researchers (Tomitch, Just, \& Newman, 2004; Hochstadt, Nakano, Lieberman, \& Friedman, 2006; Steinbrink \& Klatte, 2008). In aging, a reduction in working memory capacity may be responsible for determining a slowed and less accurate recall of propositions with higher structural syntactic demands on the sentence, but not for simpler syntactic structures, which was demonstrated by the behavioral study developed by Stine-Morrow, Shake, Miles, and Noh (2006). However, some researchers assume that these differences may not be language-specific (King \& Just, 1991; Kluender \& Kutas, 1993; Vos, Gunter, Schriefers, \& Friederici, 2001), but rather a result of changes frequently associated with aging.

Regarding the sites of brain activation, an fMRI study by Cabeza et al. (2002) and a PET study by Li, Morcom, and Rugg (2004) found increased and more diffuse frontal activation in older compared with younger adults in tasks requiring effortful retrieval and source judgments.

In a study using near-infrared spectroscopy, Scherer et al., (2007) observed higher frontal right-hemisphere activation in older adults compared with younger adults while the participants drew inferences at the macrostructural level of short narratives. The experimental condition tested the participants' ability to draw inferences by tapping into the microstructure, macrostructure, or situational model of short narratives that were visually presented. Right-hemisphere regions are known to contribute to the construction of the macrostructure of a text (St. George, Kutas, Martinez, \& Sereno, 1999). However, the elderly sample analyzed in this study appeared to have recruited extra effort to cope with 
the task and maintain good performance, as shown by the behavioral data collected regarding accuracy and revealed by the significant recruitment of frontal right-hemisphere areas.

Other studies also analyzing hemispheric contributions to cognitive processing in aging showed the recruitment of additional areas, often bilaterally, while elderly participants solved dual tasks or tasks imposing a heavy load on working memory capacity (Reuter-Lorentz et al., 2000; Smith et al., 2001).

\section{Characterizing discourse processing in aging based on behavioral evidence}

Behavioral studies on discourse processing in aging have concentrated more on text-based than situationbased representations (e.g., Stine-Morrow, Loveless, \& Soederberg, 1996; Stine-Morrow, Soederberg, \& Morrow, 1996; Miller, Cohen, \& Wingfield, 2006; Noh \& StineMorrow, 2009). These studies have shown an effect of age when there is an overload on cognitive resources, as in the case of complex syntax, high information density, or distance between anaphors and their referents in the text (Morrow, Stine-Morrow, Leirer, Andrassy, \& Kahn, 1997; Titone, Prentice, \& Wingfield, 2001).

Some behavioral studies have sought to compare discourse processing by younger adults (average age of 20 to 35 years) and older adults (average age of 60 to 75 years; Radvansky, 1999; Radvansky, Curiel, Zwaan, \& Copeland, 2001; Smiler, Gagne, \& StineMorrow, 2003). Their focus has been mainly the investigation of specificities in memory capacity, discourse comprehension in general, and forms of approaching text-based and situational levels of text. Data from these and similar studies have suggested that although younger adults' memory appears to be rooted in the text, older adults' memory appears to be rooted in its interpretation. This may explain the assumption, drawn from this literature, that younger adults exhibit better memory performance at the surface-form and propositional levels, while older adults have poorer memory performance with text-based propositions. Consequently, evidence suggests the existence of a better ability of younger adults to achieve higher levels of recall and comprehension at the micro-propositional level compared with older adults.

Regarding comprehension, although more conclusive evidence is needed, older adults appear to achieve the same (or sometimes higher) patterns of comprehension at global levels (situational model and macro-propositional level) compared with younger adults. One of the causes for this similarity (or, sometimes, advantage) may be a higher reliance by older adults on schema-based knowledge over situationspecific knowledge (Miller \& Stine-Morrow, 1998; Miller, 2009), a greater reliance on on-line contextual facilitation (Stine-Morrow, Miller, Gagne, \& Hertzog,
2008), or wider activation and maintenance of possible inferences (Hamm \& Hasher, 1992; McGinnis, 2009). However, a disadvantage that has been reported in older adults' discourse comprehension is their difficulty organizing propositions according to their informational importance (Radvansky, 1999; Stine-Morrow et al., 2006), which may in some cases, harm and slow the comprehension process.

Some of the similarities between older and younger adults' performance in discourse processing drawn from behavioral studies are the following: rapid forgetting of textbased information, a similar capacity for updating models with new information, the use of similar types of situational models, and a similar reading time in the majority of the tasks (Radvansky et al., 2001). However, researchers have not arrived at a consensus. An overall slowing in language and other cognitive processing in aging has been reported in the literature (Ska \& Joanette, 2006).

Johnson (2003) developed a meta-analytic review of studies that aimed to assess younger and older adults' performance in learning and remembering from texts by testing verbatim and substantive free recall, cued recall, recognition, and true-false verification. The differences obtained in the comparison between younger and older adults' performance varied according to text typology, learning instructions, procedures, and types of scoring methods. Age-related differences were higher for shorter texts than for longer ones. Regarding comprehension and recall versus text typology, the most difficult types of text were newspaper articles, followed by narratives, with expository texts the easiest for aged people. Descriptivetexts and narratives showed similar patterns of comprehension, and text comprehension was easier than the study of lists of unrelated sentences. Moreover, regarding the capacity for recall of narratives, a longitudinal study developed by MacDonald, Hultsch, and Dixon (2003) reported no declines in young-old adults, but rather declines in old-old adults (older than 70 years).

Finally, evidence for reduced working memory capacity detectable in higher-order language processing has been found by Tompkins, Bloise, Timko, and Baumgaertner (1994), who developed a study to investigate the relationship between working memory capacity and comprehension of passages that demanded revision of an initial interpretation. These researchers were especially interested in analyzing the role of the right hemisphere in this process. The right-hemisphere brain-damaged aged participants in their study showed a significant deficit in discourse comprehension when the task requirements where increased, a condition not observed in normal aging participants, who were in fact not expected to have problems with the task. The authors based the discussion of their results on the theory proposed by Just and Carpenter (1992), namely capacityconstrained comprehension theory. They suggested that working memory has an impact on comprehension only 
if processing demands sharply increase or if the limits of capacity are exceeded. In the case of right-hemisphere brain-damaged elderly individuals, difficulties in comprehension are linked to reduced total working memory capacity and faulty resource allocation.

Important methodological aspects must be taken into consideration when collecting and analyzing both behavioral and neuroimaging data on discourse processing in aging. Concerning the interference of experimental conditions in the assessment of reading processing in aging, many aspects have been reported to influence the different, and sometimes incongruent, data presented in the literature (Meyer \& Pollard, 2006). The authors conclude that age effects appear to be reduced when participants read longer texts compared with shorter passages, possibly because longer texts are more similar to those that they are accustomed to reading on a daily basis and from which they try to get the gist. Moreover, the differences appear to be reduced for the written mode of presentation or the simultaneous written and oral mode of presentation compared with oral presentation alone. Another aspect related to experimental designs refers to the time assigned for task resolution. Self-paced reading tasks reflect a reduced number of deficits compared with experimenter-imposed time constraints. Finally, the authors report that manual reaction-time responses elicit greater age effects compared with tasks requiring "yes" or "no" judgments or requiring the selection of a response, whereas no differences were found regarding the written versus oral mode of response.

Age-related differences generated by taskcomplexity appear to be more evident in laboratory situations but not in everyday problem-solving or job-related tasks (Finucane, Mertz, Slovic, \& Schmidt, 2005; Taylor, O’Hara, Mumenthaler, Rosen, \& Yesavage, 2005). Therefore, maintaining the experimental environment as natural as possible is important to reduce its interference with the data obtained.

\section{Final comments}

The data derived from studies, including those reviewed here, have led researchers to specify some neuropsychological bases underlying discourse (and language) processing by the elderly population. The main relationship established thus far is the one between discourse processing and working memory and executive components, such as inhibition. However, a notable limitation in these studies is the lack of evidence of oral discourse production because the main evidence is based on the written text comprehension paradigm.

With regard to neuroimaging data, only a few studies have been found, including a cognitive task with discoursive stimuli (Scherer et al., 2007; Charlton, Barrick, Markus, \& Morris, 2009). Discourse is the most complex of language components, and more studies need to be performed with discourse tasks in functional neuroimaging investigations to better comprehend discourse processing in the healthy aging brain. However, the limitations imposed by neuroimaging techniques, such as noise and the low ecological validity of the condition of reading in a scanner (e.g., with fMRI and PET) and the restricted presentation of longer texts, have caused the study of discourse by means of neuroimaging techniques to be a challenging task. Some of the main conclusions to be drawn from an analysis of brain functioning in discourse processing are that it is dependent on both cerebral hemispheres, greater participation of frontal regions appears to occur with aging, and a different pattern of neural circuitry appears to be recruited in older compared with younger adults.

The discussions developed in this review present evidence to emphasize that discourse processing in aging (and language in general, regardless of age) cannot be analyzed without considering other components of human cognition, such as memory, attention, inhibitory control, and executive function. Whenever one of these components is altered (e.g., due to aging), a change in communication functioning is expected. Therefore, studies on discourse processing should be accompanied by comprehensive analyses of cognitive capacities which are intertwined with text (and language) processing, such as those listed above and others.

Finally, highlighting that changes are not always synonymous with declines or deficits in aging is important. Factors such as the use of compensatory strategies, activation of cognitive resources accumulated throughout life, general physical and mental health conditions, and quality of life cooperate to maintain cognitive performance, including language and communication performance. Thus, further research is needed to better understand the neural correlates of cognitive function and relationships between cognitive components in aging and language processing. This comprehension can contribute to improved neuropsychological assessment tools and clinical interventions in language impairment in this population.

\section{Acknowledgments}

The second author thanks the Brazilian Ministry of Education CAPES Foundation for a Post-Doctoral scholarship (Process BEX 2231/09-3) granted during the preparation of this article.

\section{References}

Allain, P., Berrut, G., Etcharry-Bouyx, F., Barré, J., Dubas, F., \& Le Gall, D. (2007). Executive functions in normal aging: an examination of script sequencing, script sorting, and script monitoring. Journal of Gerontology: Series B. Psychological Sciences and Social Sciences, 62, 187-190.

Andrés, P., Guerrini, C., Phillips, L.H., \& Perfect, T.J. (2008). 
Differential effects of aging on executive and automatic inhibition. Developmental Neuropsychology, 33, 101-123.

Ansaldo, A.I., Monchi, O., Roy, Y., \& Doyon, J. (2005). The neural correlates of imageability and grammatical class in elderly subjects: an event-related fMRI study. Brain and Language, 95, 78-79.

Baltes, P.B. (1997). On the incomplete architecture of human ontogeny: selection, optimization, and compensation as foundation of developmental theory. American Psychologist, 52, 366-380.

Cabeza, R., Anderson, N.D., Locantore, J.K., \& McIntosh, A.R. (2002). Aging gracefully: compensatory brain activity in highperforming older adults. Neuroimage, 17, 1394-1402.

Cabeza, R., Daselaar, S.M., Dolcos, F., Prince, S.E, Budde, M., \& Nyberg, L. (2004). Task-independent and task-specific age effects on brain activity during working memory, visual attention and episodic retrieval. Cerebral Cortex, 14, 364-375.

Comición Económica para América Latina y el Caribe (2009). Estimaciones y Proyecciones de Población. [http://websie.eclac.cl/infest/ajax/cepalstat. asp?carpeta=estadisticas; accessed September 15, 2009].

Charlton, R.A., Barrick, T.R., Markus, H.S., \& Morris, R.G. (2009). Theory of mind associations with other cognitive functions and brain imaging in normal aging. Psychology and Aging, 24, 338-348.

Charlton, R.A., Barrick, T.R., Markus, H.S., \& Morris, R.G. (in press). The relationship between episodic long-term memory and white matter integrity in normal aging. Neuropsychologia.

Cook, D.B., O’Connor, P.J., Lange, G., \& Steffener, J. (2007). Functional neuroimaging correlates of mental fatigue induced by cognition among chronic fatigue syndrome patients and controls. Neuroimage, 36, 108-122.

Craik, F.I.M., \& Salthouse, T.A. (2008). The handbook of aging and cognition. New York: Psychology Press.

Davis, S.W., Dennis, N.A., Daselaar, S.M., Fleck, M.S., \& Cabeza, R. (2008). Que PASA? The Posterior-anterior shift in aging. Cerebral Cortex, 18, 1201-1209.

Dennis, N.A., \& Cabeza, R. (2008). Neuroimaging of healthy cognitive aging. In F.I.M. Craik \& T.A. Salthouse (Eds.), The handbook of aging and cognition (pp. 1-54). New York: Psychology Press.

Dolcos, F., Rice, H.J., \& Cabeza, R. (2002). Hemispheric asymmetry and aging: right hemisphere decline or asymmetry reduction. Neuroscience and Biobehavioral Reviews, 26, 819-825.

Federmeier, K.D., Van Petten, C., Schwartz, T.J., \& Kutas, M. (2003) Sounds, words, sentences: age-related changes across levels of language processing. Psychology and Aging, 18, 858-872.

Finucane, M.L., Mertz, C.K., Slovic, P., \& Schmidt, E.S. (2005). Task complexity and older adults' decision-making competence. Psychology and Aging, 20, 71-84.

Gangbè, M., \& Ducharme, F. (2006). Le «bien vieillir»: concepts et modèles. Medecine Sciences, 3, 297-300.

Gold, B.T., Andersen, A.H., Jicha, G.A., \& Smith, C.D. (2009). Aging influences the neural correlates of lexical decision but not automatic semantic priming. Cerebral Cortex, 19, 2671-2679.

Grady, C.L., Springer, M.V., Hongwanishkul, D., McIntosh, A.R., \& Winocur, G. (2006). Age-related changes in brain activity across the adult lifespan. Journal of Cognitive Neuroscience, 18, 227-241.

Hamm, V.P., \& Hasher, L. (1992). Age and the availability of inferences. Psychology and Aging, 7, 56-64.

Head, D., Buckner, R.L., Shimony, J.S., Williams, L.E., Akbudak, E., Conturo, T.E., McAvoy, M., Morris, J.C., \& Snyder, A.Z. (2004). Differential vulnerability of anterior white matter in nondemented aging with minimal acceleration in dementia of the Alzheimer type: evidence from diffusion tensor imaging. Cerebral Cortex, 14, 410-423.

Head, D., Kennedy, K.M., Rodrigue, K.M., \& Raz, N. (2009). Age differences in perseveration: cognitive and neuroanatomical mediators of performance on the Wisconsin Card Sorting Test. Neuropsychologia, 47, 1200-1203.

Hochstadt, J., Nakano, H., Lieberman, P., \& Friedman J. (2006). The roles of sequencing and verbal working memory in sentence comprehension deficits in Parkinson's disease. Brain and Language, 97, 243-257.

Johnson, R.E. (2003). Aging and the remembering of text. Developmental Review, 23, 261-346.

Just, M.A., \& Carpenter, P.A. (1992). A capacity theory of comprehension: individual differences in working memory. Psychological Review, 98, 122-149.

Kennedy, K.M., \& Raz, N. (2009). Aging white matter and cognition: differential effects of regional variations in diffusion properties on memory, executive functions, and speed. Neuropsychologia, 47, 916-927.

King, J., \& Just, M.A. (1991). Individual-differences in syntactic processing: the role of working memory. Journal of Memory and Language, 30, 580-602.

Kintsch, W., \& van Dijk, T.A. (1978). Towards a model of text comprehension and production. Psychological Review, 85, 363-394.

Kluender, R., \& Kutas, M. (1993). Bridging the gap: evidence from ERPs on the processing of unbounded dependencies. Journal of Cognitive Neuroscience, 5, 196-214.

Kramer, A.F., Fabiani, M., \& Colcombe, S.J. (2006). Contributions of cognitive neuroscience to the understanding of behavior and aging. In J.E. Birren, \& K.W. Schaie (Eds.), Handbook of the psychology of aging (pp. 57-83). New York: Elsevier.

Li, J., Morcom, A.M., \& Rugg, M.D. (2004). The effects of age on the neural correlates of successful episodic retrieval: an ERP study. Cognitive and Affective Behavioral Neuroscience, 4, 279-293.

Li, S.C., \& Dinse, H.R. (2002). Aging of the brain, sensorimotor, and cognitive processes. Neuroscience and Biobehavioral Reviews, 26, 729-732.

MacDonald, S.W.S., Hultsch, D.F., \& Dixon, R.A. (2003). Performance variability is related to change in cognition: evidence from the Victoria Longitudinal Study. Psychology and Aging, 18, 510-523.

McGinnis, D. (2009). Text comprehension products and processes in young, young-old, and old-old adults. Journal of Gerontology: Series B. Psychological Sciences and Social Sciences, 64, 202-211.

Meyer, B.J.F., \& Pollard, C.K. (2006). Applied learning and aging: a closer look at reading. In J.E. Birren, \& K.W. Schaie (Eds.), Handbook of the psychology of aging (pp. 233-261). New York: Elsevier.

Miller, L.M., Cohen, J.A., \& Wingfield, A. (2006). Contextual knowledge reduces demands on working memory during reading. Memory and Cognition, 34, 1355-1367.

Miller, L.M.S. (2009). Age differences in the effects of domain knowledge on reading efficiency. Psychology and Aging, 24, 63-74.

Miller, L.M.S., \& Stine-Morrow, E.A.L. (1998). Aging and the effects of knowledge on on-line reading strategies. Journal of Gerontology: Series B. Psychological Sciences and Social Sciences, 53, P223-P233.

Morrow, D.G., Stine-Morrow, E.A.L., Leirer, V.O., Andrassy, J.M., \& Kahn, J. (1997). The role of reader age and focus of attention in creating situation models from narratives. Journal of Gerontology: Series B. Psychological Sciences and Social Sciences, 52, P73-P80.

Noh, S.R., \& Stine-Morrow, E.A. (2009). Age differences in tracking characters during narrative comprehension. Memory and Cognition, 37, 769-778.

Nunes, M.V.S., Castro-Caldas, A., Del Rio, D., Maestú, F., \& Ortiz, T. (2009). The ex-illiterate brain: the critical period, the cognitive reserve and the HAROLD model. Dementia e Neuropsychologia, 3, 222-227.

Radvansky, G. (1999). Aging, memory, and comprehension. Current Directions in Psychological Science, 8, 49-53.

Radvansky, G.A., Curiel, J.M., Zwaan, R.A., \& Copeland, D.E. (2001). Situation models in aging. Psychology and Aging, 16, 145-160.

Rajah, M.N., Bastianetto, S., Bromley-Brits, K., Cools R., D’Esposito, M., Grady, C.L., Poirier, J., Quirion, R., Raz, N., Rogaeva, E., Song, W., \& Pruessner, J. (2009). Biological changes associated with healthy versus pathological aging: a symposium review. Ageing Research Reviews, 8, 140-146.

Raz, N. (2000). Aging and the brain and its impact on cognitive performance: integration of structural and functional findings. In F.I.M. Craik, \& T.A. Salthouse (Eds.), The handbook of aging and cognition (pp. 1-90). Mahwah, NJ: Lawrence Erlbaum Associates.

Reuter-Lorenz, P.A, Jonides, J., Smith, E.E., Hartley, A., Miller, A., Marshuetz, C., \& Koeppe, R.A. (2000). Age differences in the frontal lateralization of verbal and spatial working memory revealed by PET. Journal of Cognitive Neuroscience, 12, 174-187.

Reuter-Lorenz, P.A, \& Mikels, J.A. (2005). The aging mind and brain: implications of enduring plasticity for behavioral and cultural change. In P.B. Baltes, P.A. Reuter- Lorentz, \& F. Roesler (Eds.), Lifespan development and the brain: the perspective of biocultural coconstructivism (pp. 255-278). London: Cambridge University Press.

Scherer, L.C., Ska, B., Giroux, F., Lesage, F., Senhadji, N., Marcotte, K., Tomitch, L.M.B., Benali, H., \& Joanette, Y. (2007). Discourse 
comprehension in successful aging: a NIRS study. Brain and Language, 103, 228-229.

Silver, H., Goodman, C., Bilker, W. (2009). Age in high-functioning healthy men is associated with nonlinear decline in some "executive" functions in late middle age. Dementia and Geriatric Cognitive Disorders, 27, 292-300.

Ska, B., \& Joanette, Y. (2006). Vieillissement normal et cognition. Medecine Sciences, 22, 284-287.

Smiler, A.P., Gagne, D.D., \& Stine-Morrow, E.A.L. (2003). Aging, memory load, and resource allocation during reading. Psychology and Aging, 18, 203-209.

Smith, E.E., Geva, A., Jonides, J., Miller, A., Reuter-Lorenz, P.A., \& Koeppe, R.A. (2001). The neural basis of task-switching in working memory: effects of performance and aging. Proceeding of the National Academy of Sciences of the United States of America, 98, 2095-2100.

St. George, M., Kutas, M., Martinez, A., \& Sereno, M.I. (1999). Semantic integration in reading: engagement of the right hemisphere during discourse processing. Brain, 122, 1317-1325.

Steinbrink, C., \& Klatte, M. (2008). Phonological working memory in German children with poor reading and spelling abilities. Dyslexia, 14, 271-290.

Stemmer, B. (1999). Discourse studies in neurologically impaired populations: a quest for action. Brain and Language, 68, 402-418.

Stern, Y. (2009). Cognitive reserve. Neuropsychologia, 47, 2015-2028.

Stern, Y., Zarahn, E., Hilton, H.J., Flynn, J., De La Paz, R., \& Rakitin, B. (2003). Exploring the neural basis of cognitive reserve. Journal of Clinical and Experimental Neuropsychology, 25, 691-701.

Stine-Morrow, E.A.L., Loveless, M.K., \& Soederberg, L.M. (1996). Resource allocation in on-line reading by younger and older adults. Psychology and Aging, 11, 475-486.

Stine-Morrow, E.A.L., Miller, L.M., Gagne, D.D., \& Hertzog, C. (2008). Self- regulated reading in adulthood. Psychology and Aging, 23, 131-153.

Stine-Morrow, E.A.L., Shake, M.C., Miles, J.R., \& Noh, S.R. (2006). Adult age differences in the effects of goals on self-regulated sentence processing. Psychology of Aging, 21, 790-803.

Stine-Morrow, E.A.L., Soederberg, L.M., \& Morrow, D. (1996).
Language and discourse processing through adulthood. In T.M. Hess, \& F. Blanchard-Fields (Eds.), Perspectives on cognitive change in adulthood and aging (pp. 255-290). New York: McGraw-Hill.

Taylor, J.L., O’Hara, R., Mumenthaler, M.S., Rosen, A.C., \& Yesavage, J.A. (2005). Cognitive ability, expertise, and age differences in following air-traffic control instructions. Psychology and Aging, 20, 117-133.

Thornton, R., \& Light, L.L.(2006). Language comprehension and production in normal aging. In J.E. Birren, \& K.W. Schaie (Eds.), Handbook of the psychology of aging (pp. 261-287). New York: Elsevier.

Titone, D., Prentice, K.J., \& Wingfield, A. (2000). Resource allocation during spoken discourse processing: effects of age and passage difficulty as revealed by self-paced listening. Memory and Cognition, 28, 1029-1040.

Tomitch, L.M.B., Just, M.A., \& Newman, S. (2004). A neuroimagem funcional na investigação do processo de leitura. In C. Rodrigues, \& L.M.B. Tomitch (Eds.), Linguagem e cérebro humano: contribuições multidisciplinares (pp. 167-175). Porto Alegre, Brasil: Artmed.

Tompkins, C.A., Bloise, C.G.R., Timko, M.L., \& Baumgaertner, A. (1994). Working memory and inference revision in brain-damaged and normally aging adults. Journal of Speech, Language and Hearing Research, 37, 896-912.

Tumeh, P.C., Alavi, A., Houseni, M., Greenfield, A., Chryssikos, T., Newberg, A., Torigian, D.A., \& Moonis, G. (2007). Structural and functional imaging correlates for age-related changes in the brain. Seminars in Nuclear Medicine, 37, 69-87.

Verhaeghen, P. (2003). Aging and vocabulary scores: a meta-analysis. Psychology of Aging, 18, 332-339.

Von Faber, M., Bootsma-van der Wiel, A., Van Exel, E., Gussekloo, J., Lagaay, A.M., Van Dongen, E., Knook, D.L., Van Der Geest, S., \& Westendorp, R.G.J. (2001). Successful aging in the oldest old: who can be characterized as successfully aged? Archives of Internal Medicine, 161, 2694-2700.

Vos, S.H., Gunter, T.C., Schriefers, H., \& Friederici, A.D. (2001). Syntactic parsing and working memory: the effects of syntactic complexity, reading span, and concurrent load. Language and Cognitive Processes, 16, 65-103. 